\title{
RESEARCH
}

Open Access

\section{An integrated analysis of spatial access to the three-tier healthcare delivery system in China: a case study of Hainan Island}

\author{
Xiuli Wang ${ }^{1,2}$, Barnabas C. Seyler ${ }^{3}$, Wei $\operatorname{Han}^{4}$ and Jay $\operatorname{Pan}^{1,2^{*}}$
}

\begin{abstract}
Background: Access to healthcare is critical for the implementation of Universal Health Coverage. With the development of healthcare insurance systems around the world, spatial impedance to healthcare institutions has attracted increasing attention. However, most spatial access methodologies have been developed in Western countries, whose healthcare systems are different from those in Low- and Middle-Income Countries (LMICS).
\end{abstract}

Methods: Hainan Island was taken as an example to explore the utilization of modern spatial access techniques under China's specialized Three-Tier Health Care Delivery System. Healthcare institutions were first classified according to the three tiers. Then shortest travel time was calculated for each institution's tier, overlapped to identify eight types of multilevel healthcare access zones. Spatial access to doctors based on the Enhanced Two-Step Floating Catchment Area Method was also calculated.

Results: On Hainan Island, about $90 \%$ of the population lived within a 60-min service range for Tier 3 (hospital) healthcare institutions, 80\% lived within 30 min of Tier 2 (health centers), and 75\% lived within 15 min of Tier 1 (clinics). Based on local policy, $76.36 \%$ of the population living in $48.52 \%$ of the area were able to receive timely services at all tiers of healthcare institutions. The weighted average access to doctors was 2.31 per thousand residents, but the regional disparity was large, with 64.66\% being contributed by Tier 3 healthcare institutions.

Conclusion: Spatial access to healthcare institutions on Hainan Island was generally good according to travel time and general abundance of doctors, but inequity between regions and imbalance between different healthcare institution tiers exist. Primary healthcare institutions, especially in Tier 2, should be strengthened.

Keywords: Three-tier health care delivery system, Spatial access, Enhanced two-step floating catchment area method (E2SFCA), Overlay analysis

\footnotetext{
* Correspondence: panjie.jay@scu.edu.cn

${ }^{1}$ HEOA Group, West China School of Public Health and West China Fourth Hospital, Sichuan University, No.17 People's South Road, Chengdu 610041, China

${ }^{2}$ Institute for Healthy Cities and West China Research Center for Rural Health Development, Sichuan University, No.17 People's South Road, Chengdu, China

Full list of author information is available at the end of the article
}

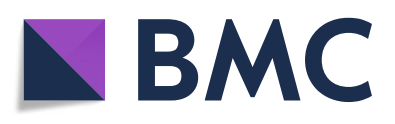

(c) The Author(s). 2021 Open Access This article is licensed under a Creative Commons Attribution 4.0 International License, which permits use, sharing, adaptation, distribution and reproduction in any medium or format, as long as you give appropriate credit to the original author(s) and the source, provide a link to the Creative Commons licence, and indicate if changes were made. The images or other third party material in this article are included in the article's Creative Commons licence, unless indicated otherwise in a credit line to the material. If material is not included in the article's Creative Commons licence and your intended use is not permitted by statutory regulation or exceeds the permitted use, you will need to obtain permission directly from the copyright holder. To view a copy of this licence, visit http://creativecommons.org/licenses/by/4.0/. The Creative Commons Public Domain Dedication waiver (http://creativecommons.org/publicdomain/zero/1.0/) applies to the data made available in this article, unless otherwise stated in a credit line to the data. 


\section{Introduction}

In 2005, the 58th World Health Assembly issued a call for Universal Health Coverage (UHC), which is defined as access to key promotive, preventive, curative, and rehabilitative health interventions for all at an affordable cost, thereby achieving equity in access $[1,2]$. Now UHC has emerged as both a global and national health priority, and progressive realization of UHC is viewed as a critical path for improving health outcomes and achieving greater equity in health across all populations [3]. Therefore, detailed and accurate assessments of current healthcare systems are essential for future healthcare planning.

Access to healthcare is central to the performance of healthcare systems around the world [4], and variability in healthcare access has been identified as a main cause for inequality in health outcomes [5]. Healthcare access is defined by five specific dimensions: 1) availability, 2) accessibility, 3) accommodation, 4) affordability, and 5) acceptability [6]. Access can be further classified as either spatial or non-spatial, or potential versus revealed access [7]. The first two dimensions are spatial in nature and refer to the number of providers available and travel impedances in reaching them, while the latter three dimensions are essentially non-spatial and reflect healthcare financing arrangements and cultural factors. The fusion of availability and accessibility has been referred to as "spatial access", which accounts for the spatial barriers that consumers must overcome to receive services [8]. Spatial access (e.g., dimensions 1-2) is also interpreted as potential access, which considers the possibility that people can access services, while revealed access depends on the willingness, preferences, and choices of individuals [9]. As an effective indicator, potential spatial access has been widely used in previous studies to measure access to healthcare and estimate equity [10].

With the improvement of healthcare insurance systems, spatial access to healthcare resources is attracting increasing attention $[11,12]$. According to a survey conducted by China's National Bureau of Statistics, during the past two decades, people's financial access to healthcare has substantially improved, while spatial access to healthcare has become the primary reason why timely utilization of healthcare does not occur [13, 14]. Generally, three factors are critical when measuring spatial access to healthcare resources: 1) the service capacity of healthcare institutions, 2) population demand, and 3) geographic impedance [15]. Service capacity refers to the amount of resources each institution possesses, such as the number of beds, physicians, or other specific facilities $[12,16]$. Population demand is the number of people who may need a particular service. Geographic impedance refers to the extent to which the distance between populations and service locations influence access
[17], with geographic distance and travel time commonly utilized.

Various methods have been developed to estimate spatial access to healthcare resources, and they can be roughly classified into four categories: 1) travel impedance to nearest provider, 2) average travel impedance to a set of providers, 3) provider-to-population ratios (PPR), and 4) the gravity model [8]. Although combining measures of travel impedance and supply is necessary to properly understand spatial access [18], travel impedance to the nearest provider has been recognized as a good measure of spatial access in certain settings, particularly where provider choices are limited and nearest providers are the most likely to be used [8]. For example, nearest providers are the most commonly-used for emergency healthcare and blood transfusion services [19-21], by pregnant women and the poor $[19,20]$, as well as in rural areas and low- and middle-income countries (LMICs) [20, 22]. Average travel impedance to providers is calculated by summing up the travel impedance from every demand point to all providers, then averaged. This method is seldom utilized, because it over-weights the influence of providers located near the periphery of the study area [8]. PPR, which is the supply to demand ratio within administrative boundaries, is the most popular type of spatial access measure due to its ease of calculation. However, PPR does not reveal spatial variations within a boundary, and it does not account for interactions between supply and demand across boundaries [23]. The gravity model overcomes the shortcomings of PPR and is theoretically more robust, but it is also complex, requiring much more computation [23].

With the development of Geographical Information System (GIS) technologies, many new methods have been introduced based on the gravity model [24, 25]. Of these, the Two-Step Floating Catchment Area (2SFCA) method has garnered the most attention [25-27]. In the 2SFCA method, a catchment of reasonable radius (e.g., distance or travel time) centered on each supply location is generated, and the PPR within this catchment is calculated. Then, a catchment of reasonable radius centered on each demand location is generated, and the PPR of supply locations within these catchments are summed up to represent the spatial access of each demand location. However, the 2SFCA method has major limitations in that it assumes equal access within the catchment and no access outside the catchment is included in the analysis [28].

A number of improvements have been proposed based on the 2SFCA, and they can be classified into four types [9]. The first modifies the distance decay function, which models the likelihood trend that choosing a healthcare institution would decrease as the distance increases [29, 30]. The second strives to improve the definition of 
catchment areas [23, 31], while the third seeks to better account for the impacts of demand or supply side competition on access $[17,32,33]$. The fourth type of improvement attempts to incorporate assumptions concerning travel behaviors of service users [34, 35]. However, a major limitation in current application is that most spatial access methodologies have been developed in Western countries, which have very different healthcare systems than developing countries. In China, the disparity of size between administrative units (usually counties) is quite large, and remote areas with limited healthcare resources are normally much larger than populous areas. Moreover, cross-boundary health seeking behaviors are very common in China, so although PPR is the most commonly used spatial access measure in Chinese government reports [36], it is not the most suitable measure.

China's healthcare system is characterized by a ThreeTier Health Care Delivery System (Table 1) [37-40]. Based on government policy, the highest tier (Tier 3) includes county hospitals in rural regions and city hospitals in urban regions, which are responsible for most inpatient services as well as teaching and research missions. All hospitals must be operated under the supervision of certain government departments to ensure their legality. The mid-level tier (Tier 2) includes township health centers (THCs, 乡镇卫生院, xiängzhèn wèishēng yuàn, in Chinese) in rural regions and community health centers/stations (CHCs) in urban regions. In certain communities where the service area or population is too large for its community health center (社区卫生服务中 心, shèqū wèishēng fúwù zhōngxīn) to handle, a community health station (社区卫生服务站, shèqū wèishēng fúwù zhàn) is established subordinate to the community health center to augment its service capacity. THCs and $\mathrm{CHCs}$ have responsibility for maintaining the public health status of their respective communities, providing public health services, preventing and treating common health problems, managing chronic diseases, and providing rehabilitation services. The front-line tier (Tier 1) institutions include village clinics (村卫生室, cūn wèishēng shi) in rural areas and community clinics (诊所, zhěnsuǒ) in urban areas, and their functions include health education, prevention, promotion, and home visits [36]. THCs (Tier 2) and village clinics (Tier 1) in rural areas, as well as $\mathrm{CHCs}$ (Tier 2) in urban areas, are funded and partially operated by local governments, so apart from providing basic clinical care, they are also responsible for many public health services [40]. Urban community clinics (Tier 1) on the other hand, are largely driven by market demands, usually being opened by registered (assistant) doctors. But, due to their having more experienced healthcare professionals (in contrast to village clinics, which tend to have less-rigorously qualified village doctors) also provide much of the primary healthcare services in urban areas [26].

Spatial access research in China has been increasing in recent years (see Appendices 1-2), apart from assessing healthcare resource allocation in different study areas (usually at the county or metropolis-level such as in

Table 1 The Three-Tier Healthcare Delivery System in China

\begin{tabular}{|c|c|c|c|c|}
\hline \multirow[t]{2}{*}{ Tier } & \multicolumn{2}{|c|}{ Healthcare institution } & \multirow[t]{2}{*}{ Function based on national documents } & \multirow[t]{2}{*}{ Local policy in Hainan Province } \\
\hline & Rural area & Urban area & & \\
\hline $\begin{array}{l}\text { Tier } \\
3\end{array}$ & $\begin{array}{l}\text { County } \\
\text { Hospitals }\end{array}$ & City Hospitals & $\begin{array}{l}\text { Diagnose and treat common and frequently- } \\
\text { occurring diseases; } \\
\text { Provide emergency treatment of emergency/ } \\
\text { severe diseases and referrals for complicated } \\
\text { diseases; } \\
\text { Provide training and guidance to primary } \\
\text { healthcare institution personnel; } \\
\text { Provide relevant public health services and }\end{array}$ & $\begin{array}{l}\text { Plan on healthcare service system of Hainan Province } \\
\text { (2015-2020) (Document number } 2015 \text { [53]) } \\
\text { By the year 2020, set up five regional medical centers in the } \\
\text { east, west, south, north, and center of Hainan Island, and } \\
\text { construct healthcare institutions in populous areas, such as } \\
\text { Wenchang, Wanning, and Dongfang, for the purpose of } \\
\text { achieving "one-hour circle to hospital care", and to treat the } \\
\text { majority of diseases within island. }\end{array}$ \\
\hline
\end{tabular}

Tier Township Community Provide basic public health services such as

2 Health Health Centers/ disease prevention and control;

Centers Stations Offer options for treatment, nursing, and rehabilitation of common health problems within the community;

Undertake management of public health services;

Provide management and technical guidance of village clinics;

Provide training of village doctors. Action plan for standardized construction of primary
healthcare institutions in Hainan Province (Document number 2018 [54])

Focus on constructing a "30-min to primary care in rural areas and 15-min to primary care in urban areas" healthcare system, to ensure safe, effective, economical, and convenient healthcare services for both urban and rural residents, to push forward the healthcare reform targets of "minor diseases not requiring travel to cities and major diseases not requiring island departure".

$\begin{array}{lll}\text { Tier } & \text { Village } & \text { Clinics } \\ 1 & \text { Clinics }\end{array}$

Provide basic public health services; Provide primary treatment of ordinary, common, and frequently occurring diseases in the village/community.

Note: The function of the three tiers of healthcare institutions was depicted according to the State Council's National Healthcare Policy-announcement of strategic plan on National Health Care Service System (2015-2020) 
Beijing or Shenzhen, but with a few analyses at the province level) [41-44], modifications on the 2SFCA method have been made to better fit the reality in China. The most common modification has been the utilization of online navigation systems based on actual travel preferences within China (e.g., public transportation, private car, etc.), which allow for real time travel impedance to be calculated to get more accurate spatial access estimates [45, 46]. Second, which tiers and/or types of healthcare institutions being considered depend on individual research questions. In most cases, the catchment area sizes of different tiers/levels/types of healthcare institutions are set differently, and general access is calculated as the sum of access for all healthcare institutions $[9,47]$. However, Zhang et al. [48] measured shortest travel time to city-level hospitals, county-level hospitals, and community-level health centers, identifying different types of healthcare resource shortage areas. However, that study's categorizations of healthcare institutions did not strictly follow government-mandated categories, and the definitions of "under-served areas" were based on patient perceptions (via interview data) without considering government guidelines or benchmarks. Existing literature provides concise indicators to express the general spatial access of healthcare resources. However, the incorporation of policy outcomes (e.g., from government or other authoritative bodies, intended to focus healthcare resource priorities) into academic studies to assess the effectives of healthcare practices has thus far been insufficient, making it difficult for governments to assess the effectiveness and weaknesses of current approaches.

In China, government guidance and investment play the central role in the healthcare system. Thus, this study sought to take Hainan Island (a relatively closedloop location within China) as a case study to assess spatial access to healthcare resources from the perspective of policy makers, and thereby provide guidance for future planning and policy making in broader contexts within China and other LMICs. Specifically, we sought to: 1) explore the utility of existing spatial access assessment methods under China's specialized Three-Tier Health Care Delivery System; 2) precisely assess the spatial access to healthcare resources on Hainan Island based on local policies; and 3) use Hainan's example to propose recommendations for future healthcare planning to policy makers.

\section{Methods}

\section{Study area}

Hainan Island, located just off the southern coast of Mainland China, is the largest populated island located entirely within the South China Sea. Hainan was selected for this study because, as an island, the cross-boundary health seeking behaviors of patients is relatively limited compared with other areas in China. Hainan Island, together with Sansha Islands, and the surrounding sea areas in the South China Sea, form Hainan Province (Fig. 1). However, almost all of Hainan Province's population is concentrated on Hainan Island. The total land area of Hainan Province is $35,191 \mathrm{~km}^{2}$, but Sansha Islands account for just $788 \mathrm{~km}^{2}$. The total population (permanent population in 2018) is 9.34 million, while just over 500 permanent residents live in Sansha Islands [49].

Transportation between Hainan Island and Mainland China relies on ships and airplanes. Ships traveling from Hai'an Harbor in Guangdong Province to Haikou City on the north end of Hainan Island take between 2 and 3 h. There are also two airports on Hainan Island, Meilan Airport in Haikou City (north end) and Fenghuang Airport in Sanya City (south end).

On Hainan Island, the coastal areas are more developed than the central region, with the island's population also distributed more densely along the coast. The road networks along the coasts are more developed, and the counties/districts there also have higher regional GDP. Overall, the central part of the island has the lowest population density, is the most mountainous, and is the least developed (Fig. 2).

\section{Data sources}

On the supply side, healthcare institution data were extracted from the yearly report of the Health Commission of Hainan Province, including Tier 3 hospitals; Tier 2 THCs and CHCs; and Tier 1 village clinics and community clinics. Community clinics were included as the first tier of the healthcare system in urban areas because community clinics provide significant numbers of basic clinical care in urban areas and include considerable numbers of registered (assistant) doctors. For example, in 2018, there were 6.12 million outpatient visits to urban community clinics in Hainan Province, compared with 7.05 million to rural village clinics. There were 3022 registered (assistant) doctors in community clinics in Hainan Province (2018), compared with just 589 in village clinics [49]. For each type of healthcare institution, we acquired basic data (e.g., name, address, type) and service capacity data (e.g., number of registered doctors and registered assistant doctors).

On the demand side, population data were collected from both WorldPop, which provides an estimate of population per grid $(100 * 100 \mathrm{~m})$ with national totals adjusted to match UN population division estimates from 2010, 2015, and 2020 [50], and the Hainan Statistical Yearbook 2019, which provides permanent population data at each county/district in 2018 [49]. The administrative boundary data, elevation data, and road network 


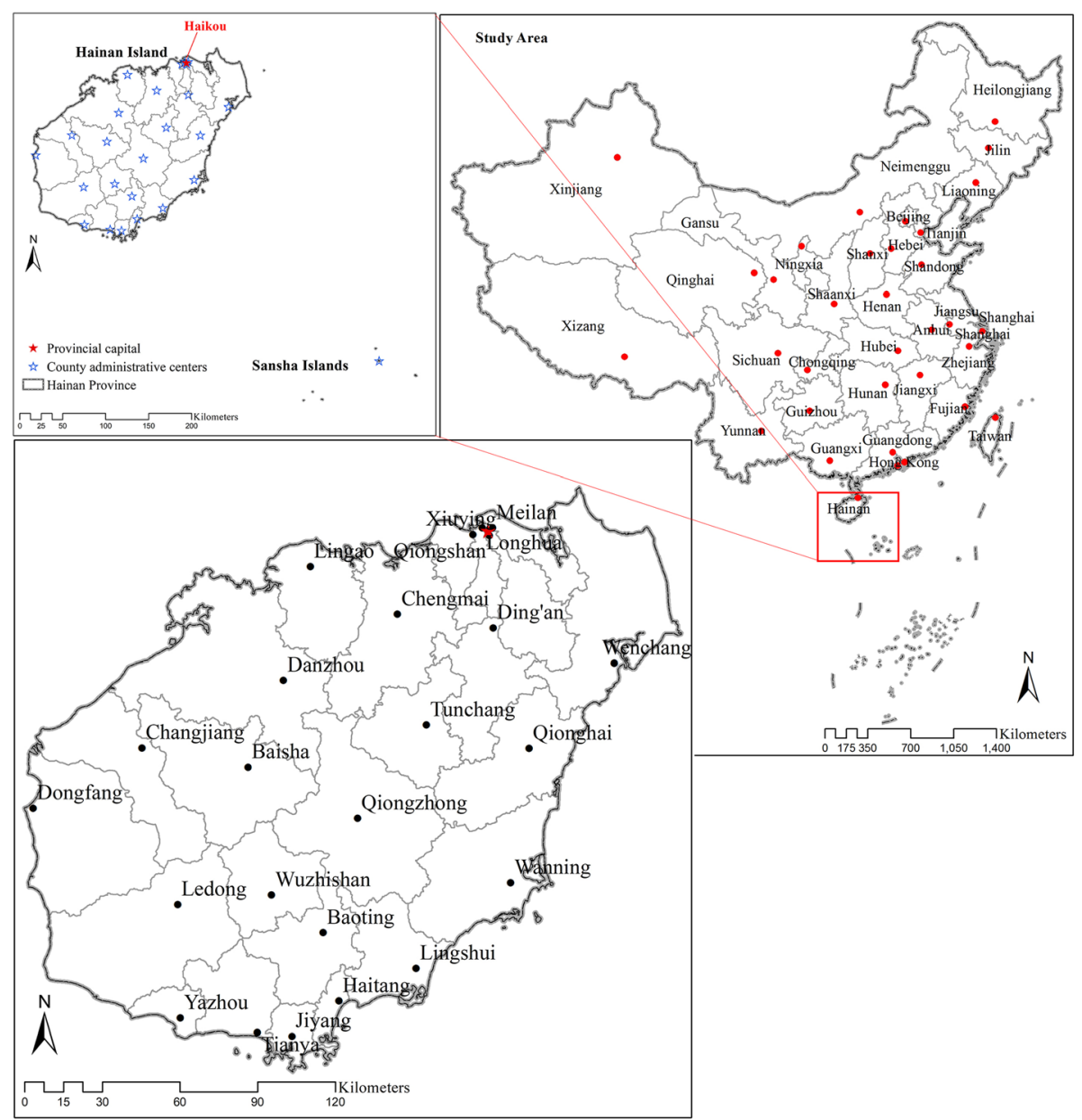

Fig. 1 Study area

data were downloaded from the National Geomatics Center of China [51].

\section{Data pretreatment}

First, all healthcare institutional data were classified according to the three healthcare system tiers. For each tier of healthcare institutions, the number of doctors (including registered doctors and registered assistant doctors) was utilized as service capacity indicators in this project. Based on the definition listed in the Health Statistics Yearbook of China 2018 [36], registered doctors and registered assistant doctors are health professionals possessing Medical Practitioner's Licenses qualifying them to carry out medical treatment and preventative healthcare, which means they are the only authorized healthcare professionals that can offer these services.

Second, population density data were adjusted based on the population data by county/district from the statistical yearbook and gridded population data from WorldPop 2015 [48]. Permanent population data from the statistical yearbook was regarded as real population data and was allocated to $100 * 100 \mathrm{~m}^{2}$ grids according to the value per cell of the WorldPop dataset, with the following formula:

$$
P_{i j}=G_{i j} *\left(\frac{T_{j}}{G_{j}}\right)
$$

Where $P_{i j}$ is the corrected population density value of grid $\mathrm{i}$ in the county/district $\mathrm{j}, G_{i j}$ is the corresponding WorldPop value of population density. $G_{j}$ is the sum of the grid values for WorldPop in county/district $\mathrm{j}$, and $T_{j}$ is the real population in the county/district $\mathrm{j}$ based on the Hainan Statistical Yearbook 2019.

Third, a geo-database containing suppliers (healthcare institutions), demanders (population density expressed as raster pixels), and geographical impedances (travel time based on road network) was established. For healthcare institutions, their longitude and latitude coordinates were compiled based on their addresses in Baidu Map, then geocoded as points in GIS. The service capacity indicators (e.g., number of doctors) were set as 

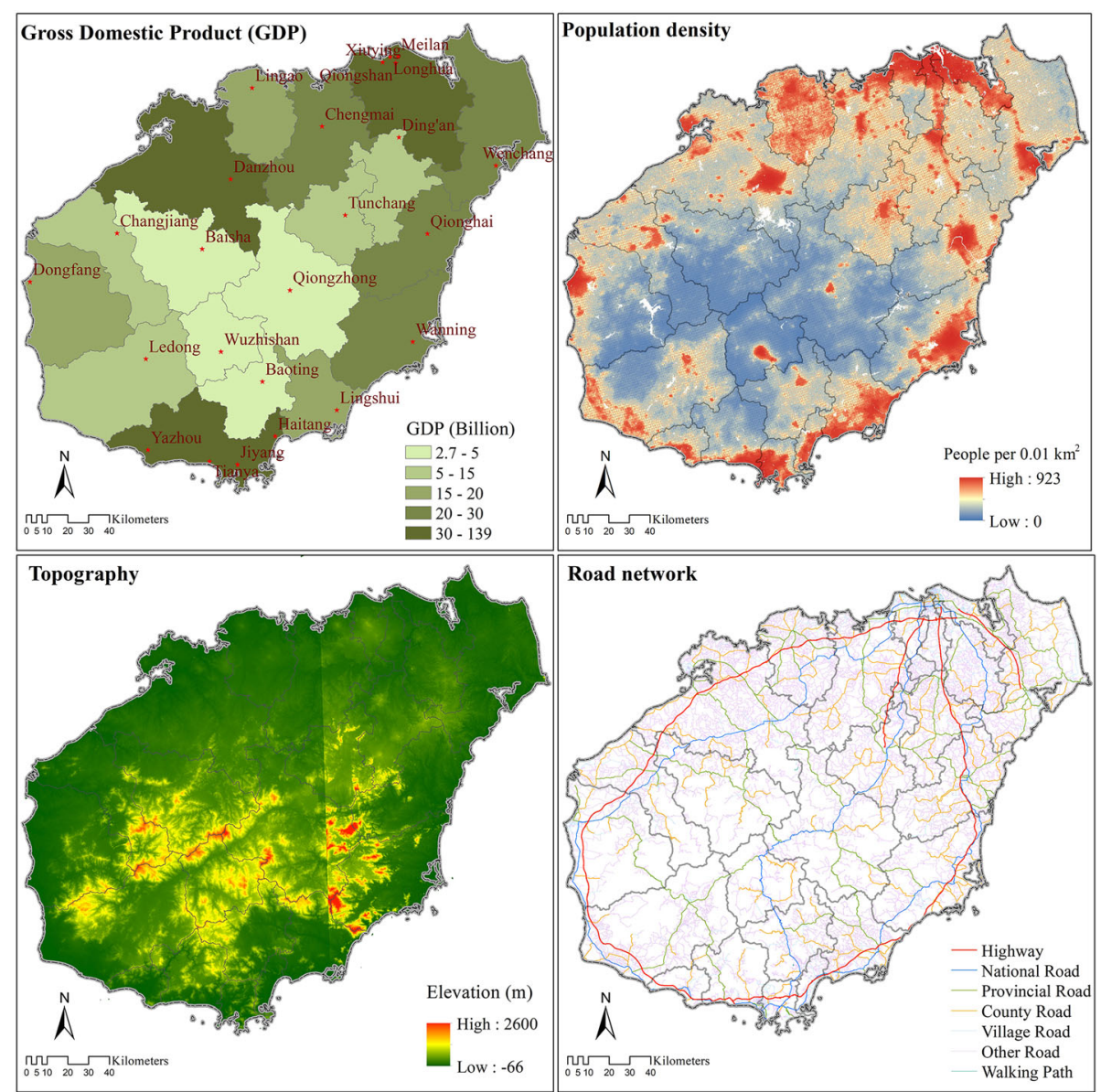

Fig. 2 Population, topography, transportation, and economic development of Hainan Island, China. Note: Population density is calculated by using the WorldPop 2015 dataset and population data extracted from Hainan Statistical Yearbook 2019. The road network data, administrative boundary data, and elevation data were collected from the National Geomatics Center of China. GDP data was collected from Hainan Statistical Yearbook 2019 (reporting data from 2018)

attributes of the points. For population density, the precision of population density data in the second step was adjusted from $100 * 100 \mathrm{~m}^{2}$ to $1 * 1 \mathrm{~km}^{2}$ by summing grid populations due to computation limitations, and every raster pixel represented a single resident point (e.g., indicating demand). The road network was classified by both type and attribute of speed class. Type of roads reveals the distribution of different roads on Hainan Island, but the travel speed of each section of road was influenced by several additional factors including road type, landscape, road width, materials, and so on. Thus, speed limits for each road section were assigned based on speed class, with the fastest being $90 \mathrm{~km} / \mathrm{h}$ and the slowest being $5 \mathrm{~km} / \mathrm{h}$. Travel time based on the road network was utilized as geographic impedance of patients receiving healthcare services.

\section{Spatial access assessment methodology}

In order to propose recommendations for future health planning to local policy makers, we assessed spatial access on Hainan Island based on local policies, including the "one-hour circle to hospital care" [52, 53] and "30-minutes to primary care in rural areas and 15minutes to primary care in urban areas" $[53,54]$ policies proposed by the Hainan Provincial Government. We also used the standard made by the State Council's National Healthcare Policy (2015-2020) that by 2020 there should be 2.50 registered (assistant) doctors for every thousand people [40]. Thus, an overlap analysis based on the Nearest-Neighbor Method, and the Enhanced Two Step Floating Catchment Area Method was utilized to assess spatial access.

\section{The nearest-neighbor method}

For the first step, the Nearest-Neighbor Method was utilized to calculate the shortest travel time for resident points (e.g., demand location). For each resident point, only the nearest healthcare institution (e.g., supply location) was considered when using the nearest-neighbor method. The travel impedance between the demand 
location and the supply location represented the convenience of receiving healthcare services. Shorter travel impedance indicates that patients can receive more timely treatment [26].

Based on the Hainan Provincial Government's "onehour circle to hospital care" and "30-minutes to primary care in rural areas and 15-minutes to primary care in urban areas" policies, the shortest travel time to the three tiers of healthcare institutions were classified into 6 categories: $0-15,15-30,30-60,60-90,90-120$, and > $120 \mathrm{~min}$. Driving time along the road network represented travel impedance, and the service area command under network analysis tools in ArcGIS 10.2 was utilized to calculate the results.

\section{Overlap analysis}

On the second step, an overlap analysis was utilized to identify different types of healthcare institution access zones (Table 2). Still based on the "one-hour circle to hospital care" and "30-minutes to primary care in rural areas and 15-minutes to primary care in urban areas" policies, timely access to healthcare institutions was defined as less than $60 \mathrm{~min}$ from the nearest hospital (Tier 3 healthcare institution), less than $30 \mathrm{~min}$ from the nearest primary healthcare institution (Tier 2 and Tier 1 ) in rural areas (e.g., THCs and village clinics), and less than $15 \mathrm{~min}$ in urban areas (e.g., $\mathrm{CHCs}$ and community clinics).

The enhanced two step floating catchment area method On the third step, the Enhanced Two Step Floating Catchment Area (E2SFCA) Method was utilized to calculate spatial access to doctors from the three tiers of

Table 2 Identification of under-served areas in terms of travel time

\begin{tabular}{ll}
\hline Type & Multilevel healthcare access zones \\
\hline A & Effective service zone \\
B & Lack of Tier 1 healthcare facilities \\
C & Lack of Tier 2 healthcare facilities \\
D & Lack of Tier 3 healthcare facilities \\
E & Lack of Tier 2 and Tier 1 healthcare facilities \\
F & Lack of Tier 3 and Tier 1 healthcare facilities \\
G & Lack of Tier 3 and Tier 2 healthcare facilities \\
H & Lack of all tiers of healthcare facilities \\
\hline
\end{tabular}

Note: The Tier 1 healthcare institutions are clinics in urban areas and village clinics in rural areas. The Tier 2 healthcare institutions are $\mathrm{CHCs}$ in urban areas and THCs in rural areas. The Tier 3 healthcare institutions are hospitals. Based on the "one-hour circle to hospital care" and "30-min to primary care in rural areas and 15-min to primary care in urban areas" policy of Hainan Province, areas that do not meet the following requirements were identified as under-served:

Tier 3 healthcare institutions: travel time to hospital $\leq 60 \mathrm{~min}$;

Tier 2 healthcare institutions: travel time to $\mathrm{THCs} \leq 30 \mathrm{~min}$ or to $\mathrm{CHCs} \leq 15 \mathrm{~min}$; Tier 1 healthcare institutions: travel time to village clinic $\leq 30 \mathrm{~min}$ or to urban clinic $\leq 15 \mathrm{~min}$ healthcare institutions. Developed to overcome the limitation of the 2SFCA Method which assumes equal accessibility within catchments and no accessibility outside catchments, the E2SFCA Method divides each catchment into multiple sub-catchments and applies different weights for each sub-catchment to model the distance decay effect [30]. The weights are defined by a weight function which can be adjusted depending on the type or importance of a service/resource [28]. The E2SFCA method has been used in a variety of studies in different regions of the world including China [15, 26, 41, 55-57]. However, previous studies have only used this method to calculate access to healthcare resources generally, but in our study we calculated access separately for each tier of healthcare institutions in order more rigorously ascertain how effectively healthcare policies (e.g., benchmarks) are being reached.

The E2SFCA Method can be represented as follows:

$$
\begin{aligned}
& R_{j}=\frac{S_{j}}{\sum_{i \in\left(d_{i j} \in D_{r}\right)} P_{k} W_{r}} \\
& A_{i}^{F}=\sum_{j \in\left(d_{i j} \in D_{r}\right)} R_{j} W_{r}
\end{aligned}
$$

The first equation calculates the supply-to-demand ratio of each healthcare institution $j$. A healthcare resource (e.g., doctors in this study) of a healthcare institution $j$ $\left(S_{j}\right.$ in eq. 1$)$ is shared by the population within the reachable range $\left(P_{k}\right.$ in eq. 1$)$, but the accessibility decreases as the reachable range (e.g., the catchment area, $D_{r}$ in Eq. [1], where $d_{k j}$ is the travel time between resident point $\mathrm{k}$ and institution $j$ ) gets further from the center (e.g., the supply point j). Distance-weights ( $W_{r}$ in Eq. [1]), derived from a distance decay function represent the decreasing trend.

The second equation calculates the spatial access of each resident point $\mathrm{i}$ ( $\mathrm{A}_{i}^{F}$ in eq. 2). The healthcare institutions that are closer to the resident point are considered more important and have higher distance-weights $\left(\mathrm{W}_{r}\right)$.

The E2SFCA method was implemented in ArcGIS 10.2. Spatial access to doctors for the three healthcare institution tiers were calculated separately. To be consistent with the Nearest-Neighbor Method, three catchment areas (0-15 $\mathrm{min}, 15-30 \mathrm{~min}, 30-60 \mathrm{~min})$ for each healthcare institution and resident point were generated, with weights being $0.880,0.316$, and 0.01 respectively $[12,26]$. The weights were calculated using Gaussian function with $\beta$ being 440. Weighted averages for spatial access of every county/district were calculated using SPSS 20.0, and Gini Coefficient of spatial access to doctors was calculated under StataSE 12 environment to measure inequality on Hainan Island [58]. 


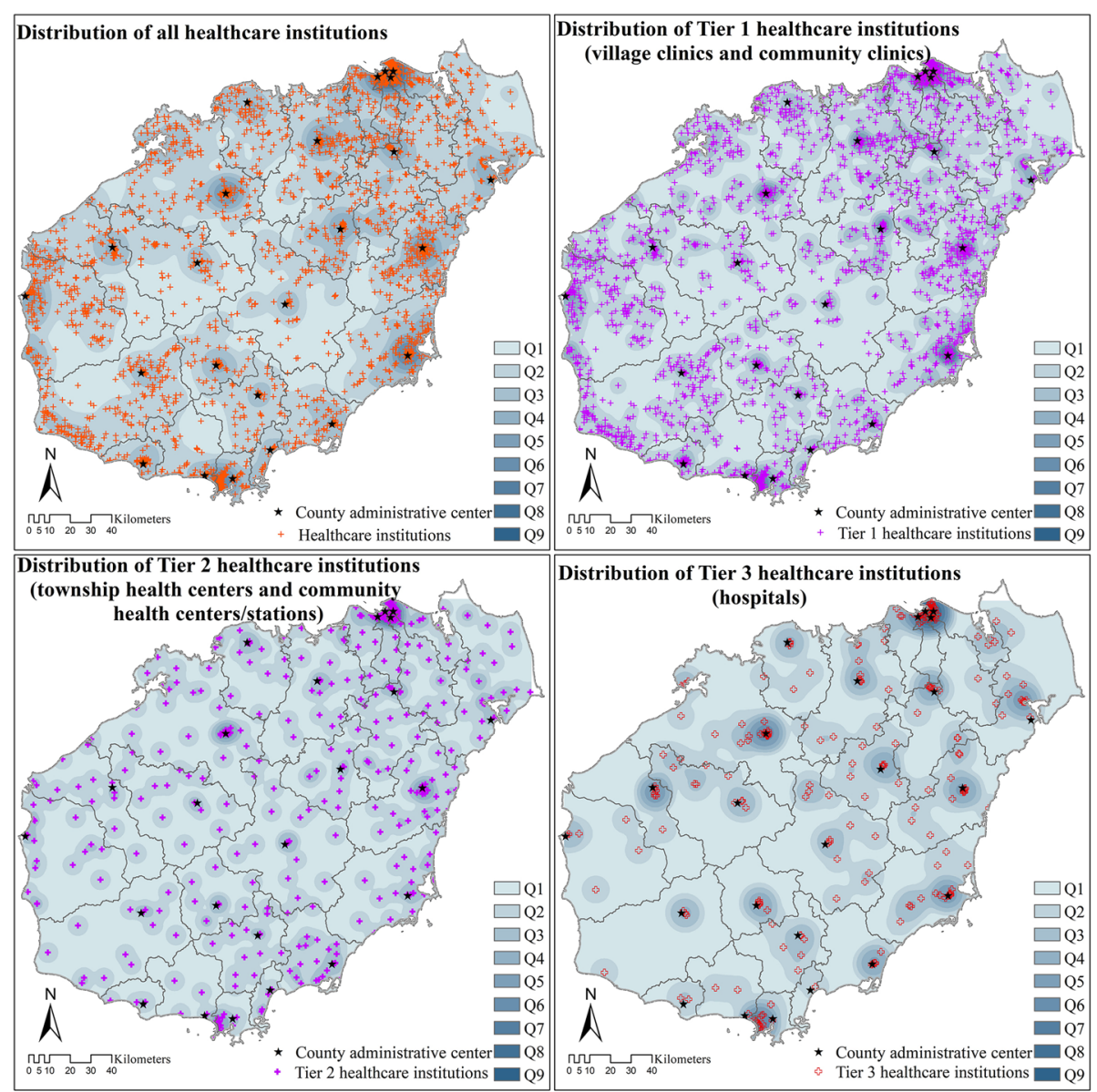

Fig. 3 Distribution of healthcare institutions on Hainan Island (2018). Note: Q1-Q9 represent the cluster degree of healthcare institutions based on Kernel Density Analysis in ArcGIS 10.2, higher numbers indicate higher cluster degree

\section{Results}

\section{General distribution of healthcare institutions on Hainan Island}

In 2018, there were 255 hospitals, 177 CHCs, 299 THCs, 1787 clinics, and 2716 village clinics on Hainan Island. The healthcare institutions were widely distributed across Hainan Island. Tier 3 healthcare institutions (hospitals) were often located near the administrative centers of each district/county, but mostly concentrated in Haikou City. Tier 2 healthcare institutions (CHCs in urban areas and THCs in rural areas) also clustered near the administrative centers, but were more evenly distributed compared to Tier 3 healthcare institutions. Nevertheless, the most significant cluster of Tier 2 healthcare institutions was also located in Haikou. The distribution of Tier 1 healthcare institutions (community clinics in urban areas and village clinics in rural areas) was most even, although Haikou still had the most significant cluster (Fig. 3).

\section{Shortest travel time to healthcare institutions}

On Hainan Island, areas further than $1 \mathrm{~h}$ from the nearest healthcare institution were all concentrated in the central mountainous region. The northeast part of Hainan Island generally showed better access to healthcare institutions than the southwest (Fig. 4).

In total, about $10 \%$ of the population ( 0.93 million) lived further than $1 \mathrm{~h}$ from the nearest Tier 3 healthcare institution, and $0.91 \%$ of the population (0.08 million) lived further than $2 \mathrm{~h}$ from the nearest Tier 3 healthcare institution. Only $3.48 \%$ (0.32 million) and $2.19 \%(0.20$ million) of the population lived further than $1 \mathrm{~h}$ from Tier 2 and Tier 1 healthcare institutions, respectively, and only about $0.3 \%$ of the population lived further than $2 \mathrm{~h}$ from any healthcare institution (Table 3).

In total $75.33 \%$ of the population lived within $15 \mathrm{~min}$ from a Tier 1 healthcare institution, and more than $90 \%$ lived within $30 \mathrm{~min}$. For Tier 2 healthcare institutions, about $50 \%$ of the population lived within a 15 -min 


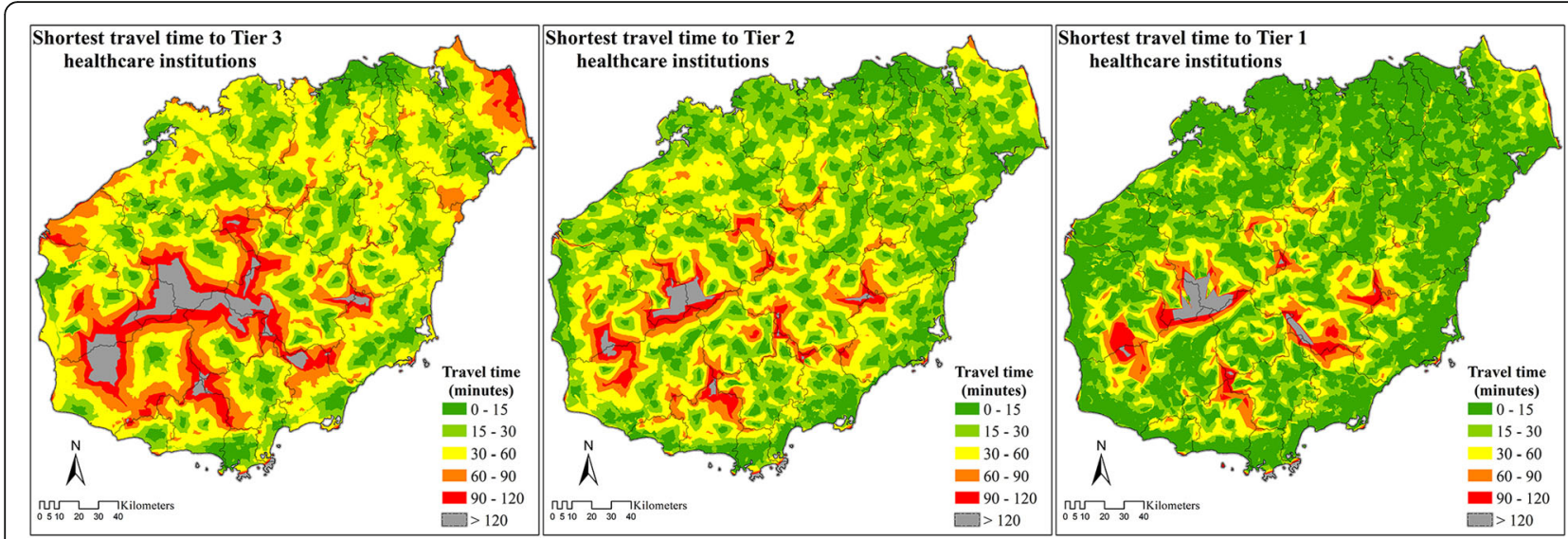

Fig. 4 Shortest travel time to the three tiers of healthcare institutions. Note: The Tier 1 healthcare institutions are clinics in urban areas and village clinics in rural areas. The Tier 2 healthcare institutions are CHCs in urban areas and THCs in rural areas. The Tier 3 healthcare institutions are hospitals

service area, and another $30 \%$ lived within a 30 -min service area. For Tier 3 healthcare institutions, about $37 \%$ of the population lived within $15 \mathrm{~min}$ of the nearest institution, accounting for 3.44 million people, the population living within the $30-60$ min service area (28.68\%) was slightly more than within the $15-30$ min service area (24.26\%) (Table 3).

\section{Overlap analysis}

On Hainan Island, more than $76 \%$ of the population (living in about $49 \%$ of Hainan Island's area) lived in Type A: effective service zone (i.e., able to receive timely service at all three tiers of healthcare institutions). Only about $5 \%$ of the population (living in $18 \%$ of the island's area) cannot receive timely service from any of the three tiers of healthcare institutions (Type $\mathrm{H}$ ). The second highest percentage of the population fell within Type $\mathrm{C}$ coverage, meaning they cannot get timely Tier 2 healthcare service (Table 4). Under-served populations were mostly located in the southwest and center of Hainan Island (Fig. 5).

\section{Spatial access to doctors}

Spatial access to doctors was not equally distributed on Hainan Island, with hotspots located near administrative centers of each county. In general, spatial access to doctors was more even and widespread for Tier 2 healthcare institutions and more evenly distributed on the northeast part of Hainan Island (Fig. 6).

The population weighted average of spatial access to doctors was 2.31 per thousand on Hainan Island, among which $64.66 \%(1.50)$ were contributed by Tier 3 healthcare institutions, $18.56 \%(0.43)$ were contributed by Tier 2 healthcare institutions, and the rest $16.78 \%(0.39)$ were contributed by Tier 1 healthcare institutions.

The Gini Coefficient of spatial access to doctors was 0.56 on Hainan Island. In contrast with the standard set by the State Council's National Healthcare Policy (2015-2020) [40], which was 2.50 doctors per thousand population by 2020 , only $32.19 \%$ of the population living in $9.21 \%$ of the area of Hainan Island met the requirement. Compared to developed countries such as Japan, the United Kingdom, and the United States, the percent population on Hainan Island reaching the average number of doctors per thousand in those countries was similarly limited (Table 5).

\section{Discussions}

Hainan Island is isolated from Mainland China with limited connection to healthcare resources outside of the

Table 3 Populations covered by the six travel zones of the three tiers of healthcare institutions

\begin{tabular}{llll}
\hline Travel zone & Tier 1 & Tier 2 & Tier 3 \\
\hline 0-15 Minutes & $7,000,677(75.33 \%)$ & $4,701,942(50.59 \%)$ & $3,442,280(37.04 \%)$ \\
$15-30$ Minutes & $1,503,997(16.18 \%)$ & $2,809,747(30.23 \%)$ & $2,254,765(24.26 \%)$ \\
30-60 Minutes & $585,316(6.30 \%)$ & $1,458,979(15.70 \%)$ & $2,665,765(28.68 \%)$ \\
60-90 Minutes & $124,836(1.34 \%)$ & $230,756(2.48 \%)$ & $652,004(7.02 \%)$ \\
$90-120$ Minutes & $49,765(0.54 \%)$ & $66,590(0.72 \%)$ & $194,815(2.10 \%)$ \\
$>120$ Minutes & $29,260(0.31 \%)$ & $25,836(0.28 \%)$ & $84,223(0.91 \%)$ \\
Total & $9,293,851(100 \%)$ & $9,293,851(100 \%)$ & $9,293,851(100 \%)$ \\
\hline
\end{tabular}

Note: Tier 1 healthcare institutions are clinics in urban areas and village clinics in rural areas. Tier 2 healthcare institutions are CHCs in urban areas and THCs in rural areas. Tier 3 healthcare institutions are hospitals 
Table 4 Percentage of area and population covered within the eight types of under-served areas in terms of travel time on Hainan Island (2018)

\begin{tabular}{llll}
\hline Type & Multilevel healthcare access zones & Area \% & Population \% \\
\hline A & Effective service zone & $48.52 \%$ & $76.36 \%$ \\
B & Lack of Tier 1 healthcare facilities & $1.02 \%$ & $0.53 \%$ \\
C & Lack of Tier 2 healthcare facilities & $13.33 \%$ & $8.81 \%$ \\
D & Lack of Tier 3 healthcare facilities & $5.16 \%$ & $2.80 \%$ \\
E & Lack of Tier 2 and Tier 1 healthcare facilities & $8.61 \%$ & $3.86 \%$ \\
F & Lack of Tier 3 and Tier 1 healthcare facilities & $0.67 \%$ & $0.30 \%$ \\
G & Lack of Tier 3 and Tier 2 healthcare facilities & $4.43 \%$ & $2.11 \%$ \\
H & Lack of all tiers of healthcare facilities & $18.27 \%$ & $5.22 \%$
\end{tabular}

Note: Tier 1 healthcare institutions are clinics in urban areas and village clinics in rural areas. Tier 2 healthcare institutions are CHCs in urban areas and THCs in rural areas. Tier 3 healthcare institutions are hospitals

island, thus it can be considered as a relatively closed-loop system for healthcare policy analysis and resource allocation. Additionally, compared with the economically advanced regions along China's eastern and southern coasts, such as Shanghai and Shenzhen, which have carried out many previous regional reforms, the Hainan Government mostly follows China's Central Government directives from Beijing. Thus, the experiences from Hainan Island have great applicability far beyond Hainan itself.

\section{Convenience of receiving healthcare services on Hainan Island}

The Hainan Provincial Government proposed the "onehour circle to hospital care" and the "30-minutes to primary care in rural areas and 15-minutes to primary care in urban areas" policies, and, based on these standards, our results show that spatial access to healthcare institutions on Hainan Island is generally effective. Of the 9.26 million people living on Hainan Island, $89.98 \%$ can

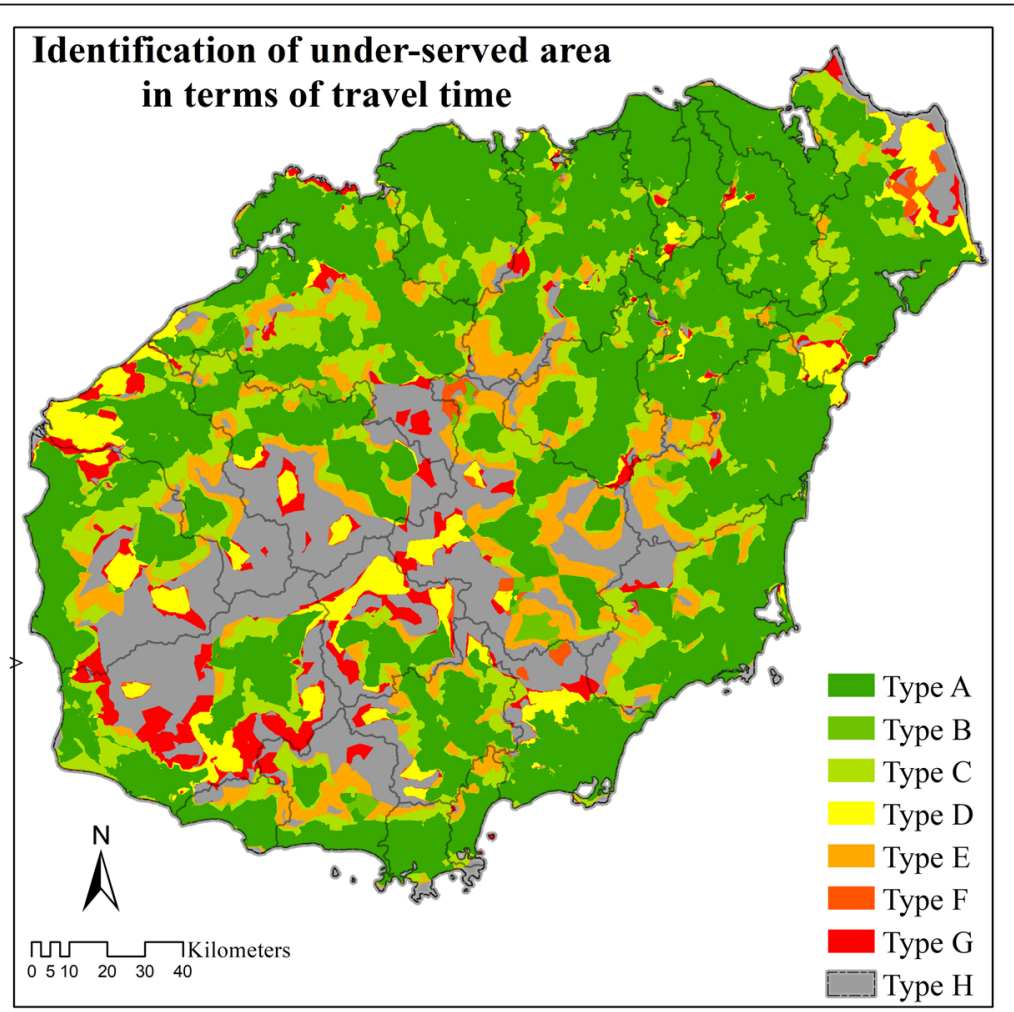

Fig. 5 Overlap analysis of shortest travel time to the three healthcare institution tiers. Note: Type A indicates coverage by all three Tiers of healthcare institutions; Type B indicates coverage by both Tier 3 and Tier 2 healthcare institutions; Type C indicates coverage by both Tier 3 and Tier 1 healthcare institutions; Type D indicates coverage by both Tier 2 and Tier 1 healthcare institutions; Type E indicates coverage by only Tier 3 healthcare institutions; Type F indicates coverage by only Tier 2 healthcare institutions; Type G indicates coverage by only Tier 1 healthcare institutions; Type $\mathrm{H}$ indicates no coverage by any healthcare institutions 

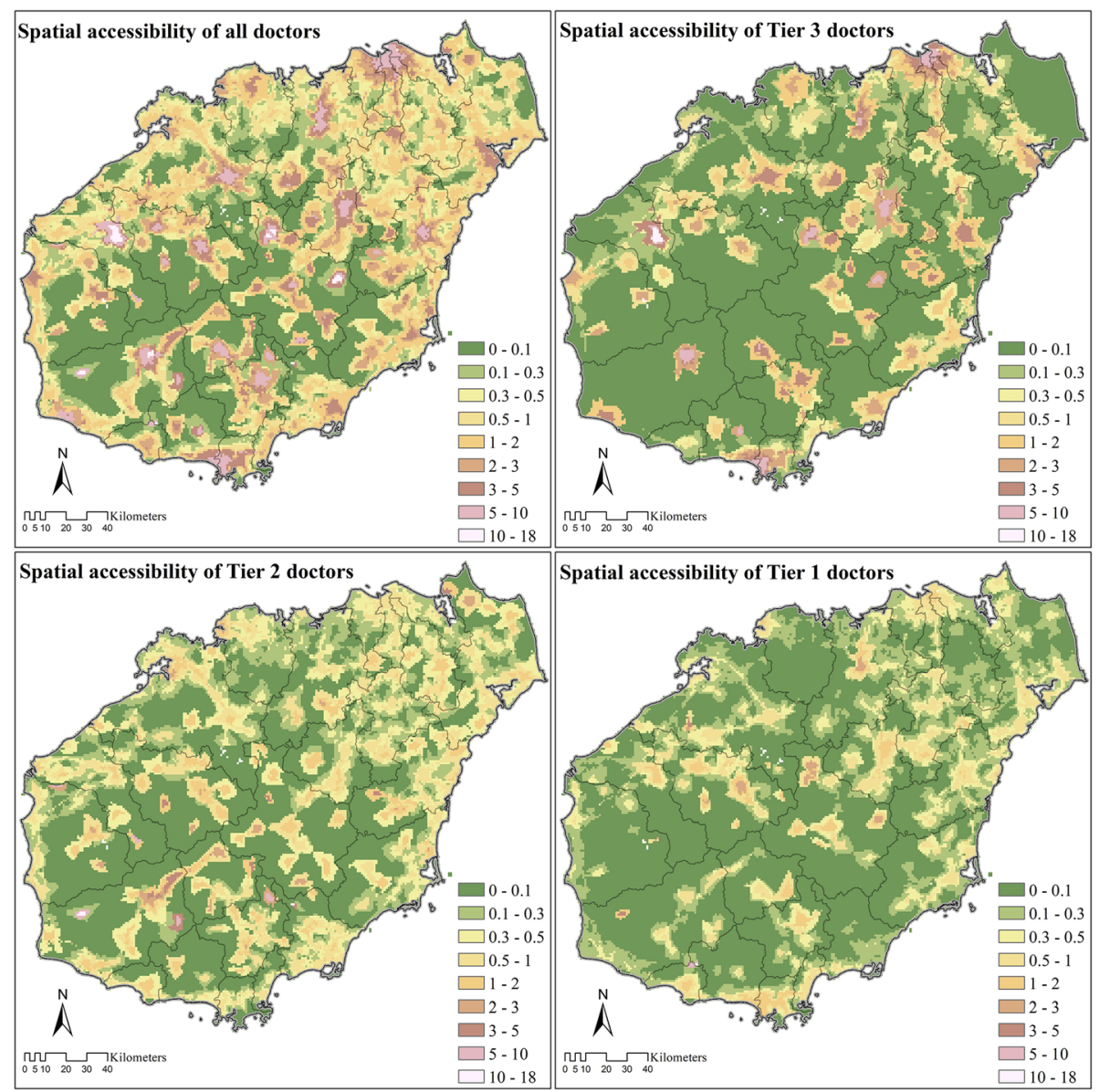

Fig. 6 Spatial access to doctors on Hainan Island. Note: The Tier 1 healthcare institutions are clinics in urban areas and village clinics in rural areas. The Tier 2 healthcare institutions are CHCs in urban areas and THCs in rural areas. The Tier 3 healthcare institutions are hospitals

access to Tier 3 healthcare institutions within $1 \mathrm{~h}$, $80.82 \%$ can access to Tier 2 healthcare institutions within $30 \mathrm{~min}$ (compared to $50.59 \%$ within $15 \mathrm{~min}$ ), and $91.51 \%$ can access to Tier 1 healthcare institutions within $30 \mathrm{~min}$ (compared to $75.33 \%$ within $15 \mathrm{~min}$ ). Thus, regardless of urbanization level, the spatial goals for Tier 3 and Tier 1 healthcare facilities have been

Table 5 Percentage of population and area on Hainan Island with access to doctors exceeding national and international standards (2018)

\begin{tabular}{llll}
\hline Country & Doctors per thousand population & Area & Population \\
\hline Japan & $2.41(2016)$ & $9.70 \%$ & $32.84 \%$ \\
China & $2.5(2020)$ & $9.21 \%$ & $32.19 \%$ \\
UK & $2.81(2017)$ & $7.84 \%$ & $30.14 \%$ \\
USA & $2.59(2016)$ & $8.78 \%$ & $31.58 \%$
\end{tabular}

Note: The standard of China was extracted from the National healthcare policy announcement of strategic plan on National healthcare service system (20152020), while the standards from Japan, UK, and USA were extracted from the Global Health Observatory (GHO) data roughly achieved. There remains, however, a relatively sizable gap for Tier 2 access.

Furthermore, the overlap analysis results show that $76.36 \%$ of Hainan's total population and $48.52 \%$ of its total area fulfilled the policy goals for timely access to healthcare. Of the different access zone types, the lack of timely Tier 2 service on Hainan Island was most significant. The underserved access zones of Type C, E, G, and $\mathrm{H}$, which relate to the lack of timely access to Tier 2 , involved $20.00 \%$ of the total population and $44.64 \%$ of Hainan's total area.

In the Three-Tier Health Care Delivery System, Tier 2 healthcare facilities are intended to function as the central hubs between Tier 3 and Tier 1 healthcare institutions [26, 38]. Although patients in China increasingly choose to access higher level hospitals [59], the Tier 2 facilities still play important roles in the healthcare system, especially in rural areas. For example, in 2018 in Hainan, the total number of outpatient visits was 50.79 million person-times, among which $39.5 \%$ were to hospitals, while $54.3 \%$ were to primary healthcare institutions. 
In addition, of the 27.59 million outpatient visits to primary healthcare institutions, $\mathrm{CHCs}$ accounted for $10.2 \%$ and THCs accounted for $41.3 \%$. The total number of inpatient visits was 1.19 million, with $86.2 \%$ occurring in hospitals and only $7.7 \%$ occurring in primary healthcare (Tier 1-2) institutions. Amongst the 0.09 million inpatient visits in primary healthcare institutions, 10.8\% occurred in CHCs, while $86.1 \%$ occurred in THCs [49]. Also, apart from basic clinical care, as primary healthcare institutions funded by the government, THCs and village clinics in rural areas, as well as $\mathrm{CHCs}$ in urban areas, are responsible for many public health services [60]. For example, they offer basic public health service packages providing 14 individual services, including health record keeping, health management of certain types of vulnerable populations, health education programs, vaccinations, etc. A primary intended purpose for Tier 2 healthcare institutions in China is to relieve pressure on Tier 3 institutions. However, on Hainan Island, greater focus should be made to improve spatial coverage for Tier 2 healthcare institutions since their coverage is currently inadequate by government standards.

On Hainan Island, areas that did not meet the government guidelines were generally concentrated in the central mountainous region. As a tourism location, visitors usually choose to go to the coastal areas, which also tend to attract large numbers of young migrant worker populations. Consequently, the central mountainous regions tend to be populated by older permanent residents. Considering the relatively less developed road network and lower GDP in the central island, residents in these under-served areas require more attention from the local government.

\section{Abundance of healthcare resources on Hainan Island}

On Hainan Island in 2018, the weighted average of spatial access to doctors was 2.31 per thousand people, which was slightly lower than the standard set by the State Council's National Healthcare Policy (2015-2020) (2.50 doctors/1000 people) [40]. It was also lower than the spatial access to doctors in some developed countries like Japan (2.41 doctors/1000), the United Kingdom (2.81 doctors/1000), and the United States (2.59 doctors/ 1000, Table 5) [61]. But unlike general practitioners which function as gatekeepers (e.g., providing referrals) to medical specialists in developed countries, health professionals in China's primary healthcare institutions tend to possess lower levels of academic degrees, technical titles, and licenses compared with health professionals working in hospitals [62]. For example, in 2017, only $30.1 \%$ of registered (assistant) doctors in hospitals lacked a university degree (graduating instead from technical high schools with medical certifications or technical colleges with associate medical degrees), however, the corresponding numbers were much higher in lower tiered healthcare institutions, including $\mathrm{CHCs}$ (55.2\%), THCs $(82.5 \%)$, and village clinics (97.7\%) [36]. So even though the absolute gap in spatial access was limited compared with developed countries, the actual differences based on medical training and knowhow is likely much greater.

The absolute total number gap in spatial access to doctors was relatively limited on Hainan Island, but the share of doctors represented by primary healthcare institutions (Tier 1 and Tier 2) seems to be problematic. On Hainan Island only $35.44 \%$ of the access to doctors was provided by these primary healthcare institutions. Under the framework of the tiered healthcare delivery system (分级诊疗, fênji zhěnliáo, in Chinese) [26, 63], which is an idealized situation envisioned for healthcare services in China [5, 60, 62], primary healthcare institutions should provide certain key services: 1) Basic public health services such as preventative care, health education, and family planning; 2) Clinical treatment for common and frequently-occurring diseases; 3) Rehabilitation and nursing services for certain diseases; and 4) Referral of patients when demand exceeds service capacity or knowhow [40]. The limited percentage of registered (assistant) doctors in primary healthcare institutions on Hainan Island did not meet the tiered health-care delivery system policy guidelines.

We also found that inequality in geographical distribution of doctor resources was significant on Hainan Island. Although the weighted average of spatial access to doctors (2.31 doctors/1000 people) was close to the national guidelines (2.5 doctors/1000), less than $1 / 3$ of Hainan's population actually enjoyed spatial access to doctors that met the guidelines (Table 5). Most of those who did were distributed in the more developed populous urban and coastal areas. This situation could be improved by increasing the percentage of healthcare resources in the lower tiers of healthcare institutions.

\section{Conclusions}

Hainan Island's population is generally well-covered by hospital care (Tier 3), but access to primary healthcare institutions (Tier 2 and Tier 1) still requires improvement, especially for Tier 2 healthcare institutions. Although access to doctors is close to national guidelines, as well as the standards of many developed countries, doctors in Hainan are unequally distributed geographically, and their distribution is not equitable across the different healthcare institution tiers.

Based on the current allocation of healthcare resources on Hainan Island, and aiming to achieve the provincial government's goals of timely access to healthcare and "Receiving Treatment at the Local Level" policy [54], we recommend that Hainan's government seek to increase 
the service capacity of primary healthcare institutions, especially for THCs and $\mathrm{CHCs}$, which are regarded as central hubs in the Three-Tier Health Care System. First, more Tier 2 healthcare institutions should be constructed to enlarge their service coverage area. Second, more healthcare resources, especially well-trained doctors should be allocated to primary healthcare institutions to improve their service capacities and quality. Third, a healthcare quality assessment system for primary healthcare institutions should be developed to monitor their operation.

Several limitations of this analysis should also be considered. First, we utilized driving time along roads to represent geographical impedance without considering the possibility of other transportation modes. Also, transportation modes might be different in urban and rural areas, while targeting different tiers of healthcare institutions [64]. Second, the distance decay function utilized in the E2SFCA method was based on previous research in other Chinese provinces, but for more accuracy future studies should adapt these for the current reality on Hainan Island. The catchment sizes might also be different for different healthcare institutions based on their tier and service capacities. Thirdly, the demand for healthcare services was considered only to population size while different socio-economic groups (age, sex, wealth, etc.) have diverse requirements [64]. As a tourism site, the seasonal tourists and migrant workers should also be considered in future healthcare resource allocation studies on Hainan Island.

\section{Supplementary Information}

The online version contains supplementary material available at https://doi. org/10.1186/s12939-021-01401-w.

Additional file 1. Literature review of spatial access to healthcare related research in China.

Additional file 2. Spatial access to healthcare publications in China over time.

\section{Abbreviations}

UHC: Universal Health Coverage; LMICs: Low- and Middle-Income Countries; E2SFCA: Enhanced Two-Step Floating Catchment Area; PPR: Provider-topopulation ratios; GIS: Geographical Information System; 2SFCA: Two-Step Floating Catchment Area; THCs: Township health centers; CHCs: Community health centers

\section{Acknowledgements}

The authors are grateful to staff from the Health Commission of Hainan Province for providing data of healthcare institutions on Hainan Island, and providing suggestions on the allocation of local healthcare resources.

\section{Authors' contributions}

XW and JP designed the study and had full access to all of the data involved in the study. XW performed the data analysis and wrote the first draft with supervision from JP. WH helped with study design, and BCS helped revising the draft. All authors contributed to interpretation of data, revised the article critically for important intellectual content, and approved the final version of the manuscript.

\section{Funding}

This study is supported by the Sichuan University Interdisciplinary Postdoc Innovation Fund and the Sichuan University Postdoc Research Foundation (\#2019SCU12013), the National Natural Science Foundation of China (\#71874116 and \#72074163), Ministry of Education of China (\#18YJA790062), Chengdu Federation of Social Science Association (\#ZZ05), and China Medical Board (\#17-276). The funders had no role in study design, data collection and analysis, decision to publish, or preparation of the manuscript.

\section{Availability of data and materials}

Part of the data that support the findings of this study are available from the Health Commission of Hainan Province, but restrictions apply to the availability of these data, which were used under license for the current study, and so are not publicly available. Data are, however, available from the authors upon reasonable request and with permission of the Health Commission of Hainan Province.

Part of the data analyzed during the current study are available from the corresponding author on reasonable request.

\section{Ethics approval and consent to participate}

All data applied in the manuscript "An integrated analysis of spatial access to the three-tier healthcare delivery system in China: A case study of Hainan Island" were extracted by corresponding government departments or from publicly available yearbooks, and no human participants were involved.

\section{Consent for publication}

Not applicable.

\section{Competing interests}

The authors declare that they have no competing interests.

\section{Author details}

${ }^{1}$ HEOA Group, West China School of Public Health and West China Fourth Hospital, Sichuan University, No.17 People's South Road, Chengdu 610041, China. ${ }^{2}$ Institute for Healthy Cities and West China Research Center for Rural Health Development, Sichuan University, No.17 People's South Road, Chengdu, China. ${ }^{3}$ Department of Environment, Sichuan University, No.24 South Section 1, Yihuan Road, Chengdu 610065, China. ${ }^{4}$ Health, Nutrition and Population Global Practice, World Bank, No.1 Jianguomenwai Street, Chaoyang district, Beijing 100020, China.

Received: 9 October 2020 Accepted: 3 February 2021

Published online: 12 February 2021

\section{References}

1. World Health Assembly. Sustainable health financing, universal coverage and Social health insurance. World Health; 2005. p. 13-6.

2. Zheng $X$, Xiong $Y, Y$, J, Deng $Z$, Zhang $X$. Analysis of government investment in primary healthcare institutions to promote equity during the three-year health reform program in China. BMC Health Serv Res. 2013;13.

3. Dieleman JL, Sadat N, Chang AY, Fullman N, Abbafati C, Acharya P, et al. Trends in future health financing and coverage: future health spending and universal health coverage in 188 countries, 2016-40. Lancet. 2018;391:1783-98.

4. Levesque JF, Harris MF, Russell G. Patient-centred access to health care: Conceptualising access at the interface of health systems and populations. Int J Equity Health. 2013;12.

5. Yip W, Fu H, Chen AT, Zhai T, Jian W, Xu R, et al. 10 years of health-care reform in China: progress and gaps in universal health coverage. Lancet. 2019;394:1192-204.

6. Penchansky R, Thomas WJ. The concept of access: Definition and relationship to consumer satisfaction. Med Care. 1981;XIX:127-40.

7. Khan AA. An integrated approach to measuring potential spatial access to health care services. Socio Econ Plan Sci. 1992;26:275-87.

8. Gaugliardo M. Spatial accessibility of primary care: concepts, methods and challenges. Int J Health Geogr 2004;13:1-13.

9. Tao Z, Cheng Y, Liu J. Hierarchical two-step floating catchment area (2SFCA) method: measuring the spatial accessibility to hierarchical healthcare facilities in Shenzhen, China. Int J Equity Health. 2020;19.

10. Gu X, Zhang L, Tao S, Xie B. Spatial accessibility to healthcare services in metropolitan suburbs: the case of qingpu, Shanghai. Int J Environ Res Public Health. 2019;16. 
11. Meng Q, Fang H, Liu X, Yuan B, Xu J. Consolidating the social health insurance schemes in China: towards an equitable and efficient health system. Lancet. 2015;386:1484-92.

12. Pan J, Liu H, Wang X, Xie H, Delamater PL. Assessing the spatial accessibility of hospital care in Sichuan Province, China. Geospat Health. 2015;10:261-70.

13. Chen T, Pan J. The effect of spatial access to primary care on potentially avoidable hospitalizations of the elderly: Evidence from Chishui City, China. Soc Indic Res. 2020;

14. National Bureau of Statistics of the People's Republic of China. Poverty monitoring report of rural China [Internet]. 2019 [cited 2021 Feb 2]. Available from: https://navi.cnki.net/KNavi/YearbookDetail?pcode= CYFD\&pykm=YPKJC\&bh $=$ (In Chinese).

15. Luo J, Chen G, Li C, Xia B, Sun X, Chen S. Use of an E2SFCA method to measure and analyse spatial accessibility to medical services for elderly people in Wuhan, China. Int J Environ Res Public Health. 2018;15.

16. Tao Z, Cheng Y, Dai T, Rosenberg MW. Spatial optimization of residential care facility locations in Beijing, China: maximum equity in accessibility. Int J Health Geogr. 2014;13.

17. Wan N, Zou B, Sternberg T. A three-step floating catchment area method for analyzing spatial access to health services. Int J Geogr Inf Sci. 2012;26:1073-89.

18. Fryer GE, Drisko J, Krugman RD, Vojir CP, Prochazka A, Miyoshi TJ, et al. Multi-method assessment of access to primary medical care in rural Colorado. J Rural Heal. 1999;15:113-21.

19. Ahmed S, Adams AM, Islam R, Hasan SM, Panciera R. Impact of traffic variability on geographic accessibility to $24 / 7$ emergency healthcare for the urban poor: a GIS study in Dhaka, Bangladesh. PLoS One. 2019;14.

20. Kuupiel D, Adu KM, Bawontuo V, Adogboba DA, Mashamba-Thompson TP. Estimating the spatial accessibility to blood group and rhesus type point-ofcare testing for maternal healthcare in Ghana. Diagnostics. 2019;9.

21. Lin Y, Wimberly MC, Da Rosa P, Hoover J, Athas WF. Geographic access to radiation therapy facilities and disparities of early-stage breast cancer treatment. Geospat Health. 2018;13:93-101.

22. Guimarães T, Lucas K, Timms P. Understanding how low-income communities gain access to healthcare services: a qualitative study in São Paulo. Brazil J Transp Heal. 2019;15.

23. Luo W, Whippo T. Variable catchment sizes for the two-step floating catchment area (2SFCA) method. Heal Place. 2012;18:789-95.

24. Nykiforuk CIJ, Flaman LM. Geographic information systems (GIS) for health promotion and public health: a review. Health Promot Pract. 2011;12:63-73.

25. Wang F, Luo W. Assessing spatial and nonspatial factors for healthcare access: towards an integrated approach to defining health professional shortage areas. Heal Place. 2005;11:131-46.

26. Wang X, Yang H, Duan Z, Pan J. Spatial accessibility of primary health care in China: a case study in Sichuan Province. Soc Sci Med. 2018;209:14-24.

27. Pan J, Zhao H, Wang X, Shi X. Assessing spatial access to public and private hospitals in Sichuan, China: the influence of the private sector on the healthcare geography in China. Soc Sci Med. 2016;170:35-45.

28. Dewulf B, Neutens T, De Weerdt Y, Van De Weghe N. Accessibility to primary health care in Belgium: an evaluation of policies awarding financial assistance in shortage areas. BMC Fam Pract. 2013;14.

29. Dai D. Black residential segregation, disparities in spatial access to health care facilities, and late-stage breast cancer diagnosis in metropolitan Detroit. Heal Place. 2010

30. Luo W, Qi Y. An enhanced two-step floating catchment area (E2SFCA) method for measuring spatial accessibility to primary care physicians. Heal Place. 2009;15:1100-7.

31. McGrail MR, Humphreys JS. Measuring spatial accessibility to primary health care services: Utilising dynamic catchment sizes. Appl Geogr. 2014;54:182-8.

32. Delamater PL. Spatial accessibility in suboptimally configured health care systems: a modified two-step floating catchment area (M2SFCA) metric. Heal Place. 2013:30-43.

33. Luo J. Integrating the huff model and floating catchment area methods to analyze spatial access to healthcare services. Trans GIS. 2014;18:436-48.

34. Mao L, Nekorchuk D. Measuring spatial accessibility to healthcare for populations with multiple transportation modes. Heal Place. 2013;24: 115-22.

35. Langford M, Higgs G, Fry R. Multi-modal two-step floating catchment area analysis of primary health care accessibility. Heal Place. 2016;38:70-81.

36. National Health Commission. Health Statistics Yearbook of China 2018 [Internet]. 2018 [cited 2020 Dec 24]. Available from: https://navi.cnki.net/KNa vi/YearbookDetail?pcode=CYFD\&pykm=YSIFE\&bh $=($ In Chinese) .
37. Feng XL, Martinez-Alvarez M, Zhong J, Xu J, Yuan B, Meng Q, et al. Extending access to essential services against constraints: the three-tier health service delivery system in rural China (1949-1980). Int J Equity Health. 2017;16.

38. Wang HHX, Wang JJ, Wong SYS, Wong MCS, Mercer SW, Griffiths SM. The development of urban community health centres for strengthening primary care in China: a systematic literature review. Br Med Bull. 2015;116:139-53.

39. Yip WCM, Hsiao W, Meng Q, Chen W, Sun X. Realignment of incentives for health-care providers in China. Lancet. 2010;375:1120-30.

40. P.R. China: State Council. National healthcare policy announcement of strategic plan on national healthcare service system (2015-2020) [Internet]. 2015 [cited 2020 Dec 24]. Available from: http://www.gov.cn/zhengce/ content/2015-03/30/content_9560.htm (In Chinese).

41. Wang $X$, Pan J. Assessing the disparity in spatial access to hospital care in ethnic minority region in Sichuan Province. China BMC Heal Serv Res. 2016;16.

42. Hu R, Dong S, Zhao Y, Hu H, Li Z. Assessing potential spatial accessibility of health services in rural China: a case study of Donghai county. Int J Equity Health. 2013;12.

43. Jin C, Cheng J, Lu Y, Huang Z, Cao F. Spatial inequity in access to healthcare facilities at a county level in a developing country: a case study of Deqing County, Zhejiang, China. Int J Equity Health. 2015:14.

44. Zhu L, Zhong S, Tu W, Zheng J, He S, Bao J, et al. Assessing spatial accessibility to medical resources at the community level in Shenzhen, China. Int J Environ Res Public Health. 2019;16.

45. Wu J, Cai Z, Li H. Accessibility of medical facilities in multiple traffic modes: a study in Guangzhou, China. Complexity. 2020;2020.

46. Tao Z, Yao Z, Kong H, Duan F, Li G. Spatial accessibility to healthcare services in Shenzhen, China: improving the multi-modal two-step floating catchment area method by estimating travel time via online map APIs. BMC Health Serv Res. 2018;18.

47. Hu W, Li L, Su M. Spatial inequity of multi-level healthcare Services in a Rapid Expanding Immigrant City of China: a case study of Shenzhen. Int J Environ Res Public Health. 2019;16.

48. Zhang S, Song $X$, Wei $Y$, Deng W. Spatial equity of multilevel healthcare in the Metropolis of Chengdu, China: a new assessment approach. Int J Environ Res Public Health. 2019:16.

49. Hainan Provincial Bureau of Statistics. Hainan statistical yearbook 2019 [Internet]. 2019 [cited 2020 Dec 24]. Available from: http://stats.hainan.gov. cn/tjj/tjsu/ndsj/ (In Chinese).

50. WorldPop. China 100m Population [Internet]. 2015 [cited 2020 Dec 24]. Available from: http://www.worldpop.org.uk/

51. National Geomatics Center of China. National basic geographic database at 1:1000000 resolution [Internet]. 2017 [cited 2020 Dec 24]. Available from: http://www.webmap.cn/commres.do?method=result100W (In Chinese).

52. The People's Government of Hainan Province. Five regional medical centers will be built in Hainan to achieve a one-hour healthcare service circle [Internet]. 2011 [cited 2020 Dec 24]. Available from: http://www.hainan.gov.cn/ hainan/5309/201110/91d4c46bc3ac4760b532d4742bbec14a.shtml (In Chinese)

53. The People's Government of Hainan Province. Plan on healthcare service system of Hainan Province (2015-2020) [Internet]. 2015 [cited 2020 Dec 24]. Available from: www.docin.com/p-1510044903.html (In Chinese).

54. The People's Government of Hainan Province. Action plan for standardizational construction of primary healthcare institutions in Hainan Province [Internet]. 2018 [cited 2020 Dec 24]. Available from: http://www.ha inan.gov.cn/hainan/szfbgtwj/201811/37479119e1d34c03934b8c0ce54dbf67. shtml (In Chinese)

55. Bauer J, Müller R, Brüggmann D, Groneberg DA. Spatial accessibility of primary Care in England: a cross-sectional study using a floating catchment area method. Health Serv Res. 2018;53:1957-78.

56. McGrail MR, Humphreys JS. Measuring spatial accessibility to primary care in rural areas: improving the effectiveness of the two-step floating catchment area method. Appl Geogr. 2009:29:533-41.

57. Ngui AN, Apparicio P. Optimizing the two-step floating catchment area method for measuring spatial accessibility to medical clinics in Montreal. BMC Health Serv Res. 2011;11.

58. Zhang T, Xu Y, Ren J, Sun L, Liu C. Inequality in the distribution of health resources and health services in China: hospitals versus primary care institutions. Int J Equity Health. 2017:16.

59. Liu Y, Kong Q, Yuan S, van de Klundert J. Factors influencing choice of health system access level in China: a systematic review. PLoS One. 2018;13: e0201887. 
60. Li X, Lu J, Hu S, Cheng KK, De Maeseneer J, Meng Q, et al. The primary health-care system in China. Lancet. 2017;390:2584-94.

61. Tobergte DR, Curtis S. Global Health Observatory (GHO) data [Internet]. Who. 2020 [cited 2020 Dec 24]. Available from: http:/www.who.int/gho/ ncd/en/

62. Liu X, Zhao S, Zhang M, Hu D, Meng Q. The development of rural primary health care in China's health system reform. J Asian Public Policy. 2015;8:88101.

63. Li X, Krumholz HM, Yip W, Cheng KK, De Maeseneer J, Meng Q, et al. Quality of primary health care in China: challenges and recommendations. Lancet. 2020;395:1802-12.

64. Ma L, Luo N, Wan T, Hu C, Peng M. An improved healthcare accessibility measure considering the temporal dimension and population demand of different ages. Int J Environ Res Public Health. 2018;15.

\section{Publisher's Note}

Springer Nature remains neutral with regard to jurisdictional claims in published maps and institutional affiliations.

Ready to submit your research? Choose BMC and benefit from:

- fast, convenient online submission

- thorough peer review by experienced researchers in your field

- rapid publication on acceptance

- support for research data, including large and complex data types

- gold Open Access which fosters wider collaboration and increased citations

- maximum visibility for your research: over $100 \mathrm{M}$ website views per year

At $\mathrm{BMC}$, research is always in progress.

Learn more biomedcentral.com/submissions 